\title{
Influencing factors and predictors of short-term normal parathyroid function after thyroidectomy: a case control study
}

\section{DunTao Su}

Xiangya Hospital Central South University https://orcid.org/0000-0002-5720-1036

\section{Fada Xia}

Xiangya Hospital Central South University

\section{Wanze Huang}

Xiangya Hospital Central South University

\section{Zhejia Zhang}

Xiangya Hospital Central South University

\section{Ning Bai}

Xiangya Hospital Central South University

\section{Di Wang}

Xiangya Hospital Central South University

xing liao

Xiangya Hospital Central South University

Xinying Li ( $\square$ lixinyingcn@csu.edu.cn )

Central South University

\section{Research article}

Keywords: Hypoparathyroidism, Hypocalcemia, Thyroidectomy

Posted Date: August 28th, 2020

DOI: https://doi.org/10.21203/rs.3.rs-60114/v1

License: (c) (1) This work is licensed under a Creative Commons Attribution 4.0 International License. Read Full License

Version of Record: A version of this preprint was published at BMC Surgery on April 21st, 2021. See the published version at https://doi.org/10.1186/s12893-021-01173-8. 


\section{Abstract \\ Background}

Postoperative hypoparathyroidism is the main reason for outpatient follow-up and long-term oral calcium and calcitriol treatment. Our study investigated the influencing factors and powerful predictors of postoperative normal parathyroid function.

\section{Methods}

Logistic regression was used to compare the clinicopathological characteristics, surgical details, and serum calcium, magnesium, and phosphorus concentrations of patients. A receiver operating characteristic (ROC) curve was used to analyze the predictors of normal parathyroid hormone (PTH).

\section{Results}

Among the 111 patients with $\mathrm{PTH}<10 \mathrm{pg} / \mathrm{mL}$ on the first postoperative day, most patients experienced a return to normal PTH (PTH $>15 \mathrm{pg} / \mathrm{mL}$ ) within 30 days postoperatively. Univariate analysis showed that Pod (postoperative day) 1PTH, Pod3 PTH, Pod7 Ca, Pod7 Mg, and Pod7 P $(\mathrm{P}<0.05)$ were associated with normal parathyroid function on the seventh postoperative day. Multivariate logistic regression analysis revealed the following independent risk factors for normal PTH levels at Pod7 after thyroidectomy: Pod3 PTH $(P=0.038)$, Pod1 PTH $(P=0.056)$, Pod7 Mg $(P=0.001)$, Pod7 P $(P=0.020)$, and the number of parathyroid glands in situ intraoperatively. The combined sensitivity of serum magnesium concentration and phosphorus concentration to predict normal parathyroid function on the seventh postoperative day was $82.76 \%$, with a sensitivity of $76.83 \%$.

\section{Conclusion}

Serum magnesium concentration, phosphorus concentration and PTH concentrations are important influencing factors and effective predictors of short-term postoperative normal parathyroid function. The surgeon should treat each parathyroid gland as the only one during the operation.

\section{Background:}

Thyroid cancer is one of the most prevalent endocrine tumors, and hypoparathyroidism is one of the most common complications after total thyroidectomy[1-3]. Accidental resection, thermal injury, or devascularization of the parathyroid glands is generally considered to be the common cause of hypoparathyroidism after thyroid surgery[4]. The need for frequent postoperative monitoring of serum ions and parathyroid function concentration, as well as regular adjustment of the dosage of calcium and calcitriol, increase the financial burden of these patients[5]. A PTH concentration of $<10 \mathrm{pg} / \mathrm{mL}$ on the 
first day after thyroid surgery has good sensitivity and specificity for predicting postoperative hypocalcemia. Calcium supplementation and calcitriol can effectively prevent the occurrence of hypocalcemia and promote the recovery of parathyroid function[6-9]. However, these treatments can cause gastrointestinal discomforts such as constipation in the short term and increase the risk of kidney stones, gout, hypercalcemia, hypercalciuria, and hyperphosphatemia[10]. Thus, high-frequency follow-up of patients treated with calcitriol and calcium is necessary. However, there are few studies on the shortterm parathyroid function return to normal after surgery in patients with hypoparathyroidism. Moreover, there is currently no consensus regarding the appropriate follow-up frequency and biochemical measures. Therefore, the purpose of this study was to investigate influencing factors and effective ionized predictors of short-term normal parathyroid function after thyroidectomy under the condition of prophylactic calcium supplementation and calcitriol.

\section{Methods:}

This was a retrospective study of patients undergoing thyroid surgery from January 2018 to May 2019 at the Department of Thyroid Surgery, Xiangya Hospital, Central South University. This study was approved and agreed upon by the Ethics Committee of Xiangya Hospital of Central South University, and all patients participating in the study provided written informed consent. All operations were performed by the same experienced surgical team. The inclusion criteria were patients with PTH levels $<10 \mathrm{pg} / \mathrm{mL}$ on the first day after thyroidectomy who could complete follow-up after surgery. The exclusion criteria were patients with a previous history of thyroid or parathyroid surgery, parathyroid disease, MEN $₫$ or II, abnormal albumin levels before or after surgery, and chronic or acute renal insufficiency. In total, 111 patients were ultimately included in the study.

\section{Patient's clinical data}

The demographic information collected from the patients included sex and age. The data collected related to the operation included the scope of the operation, the number of parathyroid glands retained in situ (PGRIS) during the operation, and the postoperative pathological results of the thyroid nodules. Biochemical indicators including preoperative serum calcium, magnesium, phosphorus, and 25hydroxyvitamin D3 levels and PTH levels, serum calcium, magnesium, and phosphorus levels were measured on days $1,3,7$, and 30 after surgery

\section{Preoperative preparation and parathyroid gland characterization}

Examinations included laryngoscopy and ultrasonography of the thyroid and neck lymph nodes before surgery. Thyroid function, PTH, albumin, and serum ions were measured within one week before surgery. The scope of surgery was determined by preoperative diagnosis. All patients defaulted to having 4 parathyroid glands in the normal position of the parathyroid gland. During the operation, the surgeon did not intentionally search for ectopic parathyroid glands and recorded the number of parathyroid glands remaining in situ (PGRIS). Intraoperative parathyroid glands are based on visual recognition, and any suspicious parathyroid tissues were sent to intraoperative frozen section pathological biopsy. The 
number of PGRIS during the operation was divided into 5 groups: group 1, no PGRIS; group 2, 1 PGRIS; group 3, 2 PGRIS; group 4, 3 PGRIS; and group 5, 4 PGRIS. The parathyroid glands that were accidentally removed or had obvious color changes during the operation were excised and preserved in $0.9 \%$ saline. A thorough examination was performed to inadvertently identify parathyroid glands in the specimen after total thyroidectomy. Parathyroid autoimplantation was performed by cutting the parathyroid glands into 1-mm-sized pieces and placing them into the ipsilateral sternocleidomastoid muscle.

\section{Postoperative management and follow-up}

The patients prophylactic received intravenous infusion of calcium gluconate $(0-2 \mathrm{~g} /$ day $)$ from the first postoperative day, as well as oral calcium (1.2-3.6 g/day) and calcitriol (0.25-0.75 $\mu \mathrm{g} / \mathrm{day})$. Once the patient develops symptomatic hypocalcemia, we will increase the dose of continuous calcium supplementation. The dose at which the patient did not develop symptomatic hypocalcemia was considered adequate. All patients were discharged on the third day after surgery. Our hospital informed these patients to follow-up on the seventh day and one month after surgery so that the parathyroid function return to normal and serum ion concentrations could be measured, and the doses of calcium and calcitriol could be adjusted. Thereafter, the same surgical team followed these patients for at least one year at 3-month intervals.

\section{Definitions}

The symptoms and signs of symptomatic hypocalcemia include numbness or tingling around the mouth and fingers, muscle spasms, or cramps in the limbs. Other signs include the Chvostek sign, Trousseau sign. Normal parathyroid function was defined as PTH $>15 \mathrm{pg} / \mathrm{mL}$ without oral calcium or calcitriol replacement therapy, hypoparathyroidism was defined as $\mathrm{PTH}<15 \mathrm{pg} / \mathrm{ml}$, and permanent hypoparathyroidism was defined as postoperative PTH $<15 \mathrm{pg} / \mathrm{mL}$ lasting for more than 1 year and requiring oral calcium or calcitriol replacement therapy. PTH levels were determined using an electrochemiluminescence immunoassay (normal reference value range is $15-65 \mathrm{pg} / \mathrm{mL}$ ), with a serum calcium concentration reference value range of 2.0-2.6 mmol/L, serum magnesium concentration reference value range of $0.66-1.07 \mathrm{mmol} / \mathrm{L}$, and serum phosphorus concentration value reference range of $0.86-1.78 \mathrm{mmol} / \mathrm{L}$.

\section{Statistical analysis}

According to the recovery trend of serum ions and PTH, linear interpolation and the linear trend of neighboring points are used for variables with missing values. These variables included the Pod3 PTH (2.7\%), Pod3 Mg (1.8\%), Pod3 Ca (1.8\%), and Pod3 P (1.8\%); Pod7 PTH (1.8\%), Pod7 Mg (5.4\%), Pod7 Ca (4.5\%), and Pod7 P (5.4\%); and Pod30 PTH (4.5\%). The optimal cut-off values for serum phosphorus concentration, serum calcium concentration, and serum magnesium concentration on the seventh postoperative day and for PTH on the first and third postoperative days were determined by receiver operating characteristic (ROC) curve analysis. This analysis method uses the maximum value of the Youden index as the cut-off value[11]. The area under the ROC curve represents the predictive power of 
laboratory parameters. Categorical variables are represented by frequency, and the data of continuous variables conforming to a normal distribution are expressed as the mean \pm standard deviation. If the data do not conform to a normal distribution, then they are expressed by the median and IQR. Continuous variables were compared using the Kruskal-Wallis test to examine the differences between groups, and categorical variables were compared using the chi-square test. If there were theoretical numbers $<10$ in the categorical variables, then Fisher's exact probability test was used to obtain the p-value. Logistic regression analysis was performed to determine the effects of these factors on normal parathyroid function on the seventh day after thyroid surgery. Statistical analysis was performed using SPSS 25.0, Medcalc 15.8, and Excel 2019. All tests were two-tailed tests, and $P<0.05$ was considered statistically significant.

\section{Results:}

Of the 111 patients with PTH $<10 \mathrm{pg} / \mathrm{mL}$ on the first day after total thyroidectomy, 92 (82.88\%) were female, with an average age of 42 years. Only $3(2.70 \%)$ patients had permanent hypoparathyroidism. Among them, 106 (95.50\%) patients had papillary thyroid cancer, 65 (58.56\%) patients underwent bilateral total thyroidectomy +CND, and $43(38.74 \%)$ patients underwent LND. On average, each patient had 3.0 parathyroid glands retained; $5(4.50 \%)$ patients did not have any parathyroid glands retained during surgery, and $43(38.74 \%)$ patients had all 4 parathyroid glands retained in situ. The specific study population characteristics are listed in Table. 1

\section{The parathyroid function return to normal and the changing trend of serumions within 1 month after thyroidectomy.}

In this study, parathyroid function returned to normal on the third postoperative day in only one patient $(0.90 \%)$, while it returned to normal on the seventh postoperative day in a total of 29 patients $(26.13 \%)$ and on the thirtieth postoperative day in a total of 97 patients (87.39\%). The recovery of patients with hypoparathyroidism after surgery is shown in Figure 1 (Fig 1). The change trends in serum $\mathrm{Ca}, \mathrm{Mg}$, and $\mathrm{P}$ concentrations before and after surgery are shown in Figure 2 (Fig 2).

\section{The predictive effect of serum $\mathrm{Mg}$ concentration and serum $\mathrm{P}$ concentration on normal parathyroid function on the seventh postoperative day}

The predictive effect of Pod7 Mg and Pod7 P on normal parathyroid function on the seventh postoperative day was determined using ROC curve analysis, and the results are shown in Fig 3 . The optimal cut-off values for serum ions on the seventh postoperative day and blood PTH levels on the first and third postoperative days were Pod7 Mg> $0.8 \mathrm{mmol} / \mathrm{l}$, Pod7 P $\leq 1.51 \mathrm{mmol} / \mathrm{l}$, Pod7 Ca> $2.05 \mathrm{mmol} / \mathrm{l}$, Pod1 PTH $>5.18 \mathrm{pg} / \mathrm{mL}$, and Pod7 PTH> $5.6 \mathrm{pg} / \mathrm{mL}$. The combined sensitivity and specificity of serum $\mathrm{Mg}$ and $\mathrm{P}$ concentrations to predict normal PTH on the seventh day after total thyroidectomy were $82.76 \%$ and $76.83 \%$, respectively. This is superior to the diagnostic performance of Pod7 Mg, Pod7 P, Pod1 PTH, or Pod3 PTH alone (Table 2). 


\section{Influencing factors of normal parathyroid function on the seventh postoperative day}

Univariate analysis showed that Pod1 PTH $(\mathrm{P}<0.05)$, Pod3 PTH $(\mathrm{P}<0.05)$, Pod7 Mg $(\mathrm{P}<0.05)$, Pod7 Ca $(\mathrm{P}$ $<0.05)$, and Pod7 $P(P<0.05)$ were the influencing factors of normal parathyroid function on the seventh day after surgery (Table 3 ). However, the scope of surgery was not a factor influencing the return of PTH to normal after surgery. Intraoperative PGRIS (OR 0.025 P = 0.025), Pod3 PTH>5.6 pg/mL (OR $3.745 \mathrm{P}=$ 0.038), Pod1 PTH> 5.18 pg/mL (OR $3.439 \mathrm{P}=0.056), \mathrm{Pod} 7 \mathrm{Mg} \geq 0.8 \mathrm{mmol} / \mathrm{I}(\mathrm{OR} 19.221 \mathrm{P}=0.001)$ and Pod7 $\mathrm{P} \leq 1.51 \mathrm{mmol} / \mathrm{I}(\mathrm{OR} 4.475 \mathrm{P}=0.02)$ were included in the final multifactor analysis equation, and the results are shown in Table 4.

\section{Discussion:}

Hypoparathyroidism is one of the most common complications after total thyroidectomy. Some studies have found that calcium and calcitriol supplementation can aid the recovery of parathyroid function in patients with hypoparathyroidism[7, 12-14]. In agreement with previous findings[13, 15], in the present study, parathyroid function in most patients returned to normal within 1 month (87.39\%) after the operation, and intraoperative PGRIS scores was an independent influencing factor for the return of normal PTH after surgery. In addition, we found that serum ion concentrations were predictors of parathyroid function return to normal on the seventh postoperative day. Some scholars believe that intraoperative PGRIS, intraoperative accidental resection, and the number of parathyroid glands that are autotransplanted are not influencing factors for postoperative hypocalcemia[16, 17]. However, the surgical methods in these studies are relatively conservative, and the sample sizes are relatively small and less representative of the population of patients undergoing total thyroidectomy. Surgeons should treat each parathyroid gland as the only parathyroid gland during the operation.

Studies have shown that the scope of surgery is a risk factor for hypoparathyroidism after thyroid surgery[18-20]. The greater the scope of the operation is, the greater the chance of parathyroid gland parenchyma damage, blood vessel damage, and accidental resection. However, during the recovery of parathyroid function, scholars have found that intraoperative PGRIS is a more effective variable than the scope of surgery and found that the surgical scope is not an independent influencing factor for postoperative recovery of parathyroid function $[13,15]$. Our research found similar results. Our results indicate that the effect of the scope of surgery on hypoparathyroidism is not statistically significant. There are two potential explanations for this finding. On the one hand, the scope of the operation may have little effect on parathyroid function return to normal after surgery; on the other hand, most of the patients in this study (108 96.34\%) underwent bilateral total thyroidectomy + CND, and LND could not be performed independently of CND. Parathyroid function recovery is a dynamic process. Pod1 PTH and Pod3 PTH represent the baseline level of parathyroid function recovery. The higher Pod1 PTH and Pod3 PTH, the easier it is to recover parathyroid function after surgery. Although the $p$-value of Pod1 PTH> 5.18 $\mathrm{pg} / \mathrm{mL}$ was greater than $0.05(\mathrm{P}=0.056)$, it was retained in the stepwise forward logistic regression results output by SPSS. Because of its greater influence on the equation, combined with its clinical relevance and impact on the logistic regression model, this variable is still considered meaningful. 
During the recovery of parathyroid function, multiple ions work in concert. From a physiological point of view, the decrease in the serum magnesium concentration after thyroid surgery inhibits PTH secretion and thus increases the resistance of terminal organs to PTH[21, 22]. PTH increases the reabsorption of magnesium by the renal tubules, and high phosphorus concentrations stimulate the secretion of PTH[23, 24]. Our study also found that normal parathyroid function after total thyroidectomy was associated with Pod7 Mg and Pod7 P levels. The multivariate analysis results showed that serum magnesium concentration and phosphorus concentration were independent factors influencing the return of Pod7 PTH to normal, and patients with Pod7 $\mathrm{Mg}>0.8 \mathrm{mmol} / \mathrm{l}$ and Pod7 $\mathrm{P} \leq 1.51 \mathrm{mmol} / \mathrm{l}(\mathrm{P}<0.05)$ experience a more rapid return to normal parathyroid function. Thus, it is necessary to detect ions other than calcium ions after thyroid surgery.

Parathyroid hormone is the main hormone regulating calcium ions. Hypocalcemia often occurs after hypoparathyroidism. Some scholars have reported that the magnesium concentration after thyroid surgery is closely related to hypoparathyroidism[25-28]. We also find that Pod7 Mg and Pod7 P are effective predictors of the return of PTH to normal levels on Pod7. The combined sensitivity of serum Mg and $\mathrm{P}$ concentrations to predict normal parathyroid function was $82.76 \%$, and the specificity was $76.83 \%$. The predictive effect of rapid biochemical indicators on parathyroid function will be helpful for clinicians to diagnose and better manage the dosage of calcium tablets and calcitriol in patients. In addition, many scholars have explored the predictive effect of short-term PTH after thyroid surgery [6-9]. However, many junior hospitals do not have the equipment to detect PTH, or the test is too time-consuming. From the perspective of medical expenses, ion prediction can reduce the cost of parathyroid function testing.

Serum PTH concentration and serum magnesium concentration showed a downward trend within 1-2 days after total thyroidectomy, whereas serum ionized phosphorus showed an upward trend, and a gradual return to the preoperative level. Some scholars have previously explored the changes in serum ionized calcium, magnesium, and phosphorus on day 1 and day 2 after total thyroidectomy[28, 29]. However, our study further explored the change trend in postoperative calcium, magnesium, and phosphorus ion concentrations within the first month after surgery. This study also has some limitations related to its retrospective nature. The study protocol required follow-up of patients' recovery of parathyroid function and serum ions within 1, 3, 7, 30 days, and 1 year after surgery. We conservatively estimate those patients' parathyroid function has returned to normal, which may lead to overestimation of parathyroid function recovery. Hypoparathyroidism, postoperative preventive calcium and calcitriol supplementation can affect the measurement of real postoperative serum calcium and calcitriol concentrations.

\section{Conclusion:}

We found that serum magnesium concentration, phosphorus concentration and PTH concentration are important influencing factors and effective predictors of short-term postoperative parathyroid function return to normal. In addition, we explored the trends of biochemical indicators after thyroid surgery. The surgeon should treat each parathyroid gland as the only parathyroid gland during the operation. 


\section{Abbreviations}

PTH: parathyroid hormone; PGRIS: parathyroid glands remaining in situ; Pod: postoperative day; Pre: preoperative; TT: total thyroidectomy; CND: central lymph node dissection; LND: lateral lymph node dissection; ROC: receiver operating characteristic; AUC: Area under the ROC curve; SE: Standard error; Cl: Confidence interval; PPV: positive predictive value; NPV: negative predictive value

\section{Declarations}

\section{Acknowledgements}

Not applicable.

\section{Authors'contributions}

All authors participated in the study. XL designed the study; DS and WH collected the data. DS drafted the manuscript and analyzed the data and reviewed the manuscript; FX, WD critically revised the manuscript for important

intellectual content; NB, ZZ and XL reviewed the manuscript and contributed for final approval. All authors have reviewed and approved the final version of the manuscript.

\section{Funding}

This work was funded by the National Natural Science Foundation of China (81672885).

\section{Availability of data and materials}

The datasets used and/or analyzed during the current study are available from the corresponding author on reasonable request.

\section{Ethics approval and consent to participate}

This study was approved and agreed upon by the Ethics Committee of Xiangya Hospital of Central South University, and all patients participating in the study provided written informed consent.

\section{Consent for publication}

Not applicable.

\section{Competing interests}

The authors declare that they have no competing interests.

\section{References}


1. Xia F, Wang W, Jiang B, Chen Y, Li X: DNA methylation-mediated silencing of miR-204 is a potential prognostic marker for papillary thyroid carcinoma. Cancer Manag Res 2019, 11:1249-1262.

2. Xia F, Chen Y, Jiang B, Du X, Peng Y, Wang W, Huang W, Feng T, Li X: Long Noncoding RNA HOXA-AS2 Promotes Papillary Thyroid Cancer Progression by Regulating miR-520c-3p/S100A4 Pathway. Cell Physiol Biochem 2018, 50(5):1659-1672.

3. Xia F, Jiang B, Chen Y, Du X, Peng Y, Wang W, Wang Z, Li X: Prediction of novel target genes and pathways involved in tall cell variant papillary thyroid carcinoma. Medicine (Baltimore) 2018, 97(51):e13802.

4. El Malki HO, Abouqal R: Systematic review and meta-analysis of predictors of post-thyroidectomy hypocalcaemia (Br J Surg 2014; 101: 307-320). Br J Surg 2014, 101(7):883.

5. McCullough M, Weber C, Leong C, Sharma J: Safety, efficacy, and cost savings of single parathyroid hormone measurement for risk stratification after total thyroidectomy. Am Surg 2013, 79(8):768-774.

6. Wang W, Xia F, Meng C, Zhang Z, Bai N, Li X: Prediction of permanent hypoparathyroidism by parathyroid hormone and serum calcium 24h after thyroidectomy. Am J Otolaryngol 2018, 39(6):746-750.

7. Villarroya-Marquina I, Sancho J, Lorente-Poch L, Gallego-Otaegui L, Sitges-Serra A: Time to parathyroid function recovery in patients with protracted hypoparathyroidism after total thyroidectomy. Eur J Endocrinol 2018, 178(1):103-111.

8. Lindblom P, Westerdahl J, Bergenfelz A: Low parathyroid hormone levels after thyroid surgery: A feasible predictor of hypocalcemia. Surgery 2002, 131(5):515-520.

9. Selberherr A, Scheuba C, Riss P, Niederle B: Postoperative hypoparathyroidism after thyroidectomy: efficient and cost-effective diagnosis and treatment. Surgery 2015, 157(2):349-353.

10. Gupta S, Chaudhary P, Durga CK, Naskar D: Validation of intra-operative parathyroid hormone and its decline as early predictors of hypoparathyroidism after total thyroidectomy: A prospective cohort study. Int J Surg 2015, 18:150-153.

11. Al-Dhahri SF, Mubasher M, Mufarji K, Allam OS, Terkawi AS: Factors predicting post-thyroidectomy hypoparathyroidism recovery. World J Surg 2014, 38(9):2304-2310.

12. Jarhult $\mathrm{J}$, Landerholm $\mathrm{K}$ : Outcome of hypocalcaemia after thyroidectomy treated only in symptomatic patients. Br J Surg 2016, 103(6):676-683.

13. Sitges-Serra A, Ruiz S, Girvent M, Manjon H, Duenas JP, Sancho JJ: Outcome of protracted hypoparathyroidism after total thyroidectomy. Br J Surg 2010, 97(11):1687-1695.

14. Roh JL, Park JY, Park Cl: Prevention of postoperative hypocalcemia with routine oral calcium and vitamin $\mathrm{D}$ supplements in patients with differentiated papillary thyroid carcinoma undergoing total thyroidectomy plus central neck dissection. Cancer 2009, 115(2):251-258.

15. Lorente-Poch L, Sancho JJ, Ruiz S, Sitges-Serra A: Importance of in situ preservation of parathyroid glands during total thyroidectomy. Br J Surg 2015, 102(4):359-367. 
16. Sasson AR, Pingpank JF, Jr., Wetherington RW, Hanlon AL, Ridge JA: Incidental parathyroidectomy during thyroid surgery does not cause transient symptomatic hypocalcemia. Arch Otolaryngol Head Neck Surg 2001, 127(3):304-308.

17. Sakorafas GH, Stafyla V, Bramis C, Kotsifopoulos N, Kolettis T, Kassaras G: Incidental parathyroidectomy during thyroid surgery: an underappreciated complication of thyroidectomy. World J Surg 2005, 29(12):1539-1543.

18. Thomusch O, Machens A, Sekulla C, Ukkat J, Brauckhoff M, Dralle H: The impact of surgical technique on postoperative hypoparathyroidism in bilateral thyroid surgery: a multivariate analysis of 5846 consecutive patients. Surgery 2003, 133(2):180-185.

19. Su A, Wang B, Gong Y, Gong R, Li Z, Zhu J: Risk factors of hypoparathyroidism following total thyroidectomy with central lymph node dissection. Medicine (Baltimore) 2017, 96(39):e8162.

20. Paek SH, Lee YM, Min SY, Kim SW, Chung KW, Youn YK: Risk factors of hypoparathyroidism following total thyroidectomy for thyroid cancer. World J Surg 2013, 37(1):94-101.

21. Quitterer $U$, Hoffmann M, Freichel M, Lohse MJ: Paradoxical block of parathormone secretion is mediated by increased activity of $\mathbf{G}$ alpha subunits. J Biol Chem 2001, 276(9):6763-6769.

22. Tong GM, Rude RK: Magnesium deficiency in critical illness. J Intensive Care Med 2005, 20(1):3-17.

23. Bergwitz C, Juppner H: Regulation of phosphate homeostasis by PTH, vitamin D, and FGF23. Annu Rev Med 2010, 61:91-104.

24. Houillier P: Mechanisms and regulation of renal magnesium transport. Annu Rev Physio/ 2014, 76:411-430.

25. Wang W, Meng C, Ouyang Q, Xie J, Li X: Magnesemia: an independent risk factor of hypocalcemia after thyroidectomy. Cancer Manag Res 2019, 11:8135-8144.

26. Luo $\mathrm{H}$, Yang $\mathrm{H}$, Zhao W, Wei T, Su A, Wang B, Zhu J: Hypomagnesemia predicts postoperative biochemical hypocalcemia after thyroidectomy. BMC Surgery 2017, 17(1).

27. Wilson RB, Erskine $\mathrm{C}$, Crowe $\mathrm{PJ}$ : Hypomagnesemia and hypocalcemia after thyroidectomy: prospective study. World J Surg 2000, 24(6):722-726.

28. Brophy C, Woods R, Murphy MS, Sheahan P: Perioperative magnesium levels in total thyroidectomy and relationship to hypocalcemia. Head Neck 2019, 41(6):1713-1718.

29. Sousa Ade A, Salles JM, Soares JM, Moraes GM, Carvalho JR, Savassi-Rocha PR: Evolution of blood magnesium and phosphorus ion levels following thyroidectomy and correlation with total calcium values. Sao Paulo Med J 2010, 128(5):268-271.

\section{Tables}

Table 1 Characteristics of the study population $(\mathrm{N}=111)$ 


\begin{tabular}{|c|c|c|}
\hline Characteristics & $\mathrm{n}$ & value \\
\hline Age, years & 111 & $41(32-51)$ \\
\hline Sex & 111 & \\
\hline Male & $19(17.12 \%)$ & NA \\
\hline Female & $92(82.88 \%)$ & NA \\
\hline Vitamin D (ng/ml) & 111 & $21.10(16.52-27.41)$ \\
\hline \multicolumn{3}{|l|}{ Hyperthyroidism } \\
\hline Yes & $1(0.90 \%)$ & NA \\
\hline No & $110(99.10 \%)$ & NA \\
\hline \multicolumn{3}{|l|}{ Scope of surgery } \\
\hline TT & $3(2.70 \%)$ & NA \\
\hline TT+CND & $65(58.56 \%)$ & NA \\
\hline TT+CND+LND & $43(38.74 \%)$ & NA \\
\hline \multicolumn{3}{|l|}{ Thyroid pathology } \\
\hline Goiter & $5(4.50 \%)$ & NA \\
\hline Carcinoma & $106(95.50 \%)$ & NA \\
\hline \multicolumn{3}{|l|}{ PGRIS } \\
\hline 0 & $5(4.50 \%)$ & NA \\
\hline 1 & $5(4.50 \%)$ & NA \\
\hline 2 & $19(17.12 \%)$ & NA \\
\hline 3 & $39(35.14 \%)$ & NA \\
\hline 4 & $43(38.74 \%)$ & NA \\
\hline Preoperative PTH (pg/mL) & 111 & $39.27(16.52-27.41)$ \\
\hline Preoperative $\mathrm{Ca}(\mathrm{mmol} / \mathrm{l})$ & 111 & $2.35(0.09)$ \\
\hline Preoperative $\mathrm{Mg}(\mathrm{mmol} / \mathrm{l})$ & 111 & $0.89(0.84-0.92)$ \\
\hline Preoperative P (mmol/l) & 111 & $1.17(0.19)$ \\
\hline \multicolumn{3}{|c|}{ Characteristics at postoperative day 1} \\
\hline Pod1 PTH (pg/mL) & 111 & $5.13(3.70-6.97)$ \\
\hline Pod1 Ca (mmol/l) & 111 & $1.98(0.12)$ \\
\hline
\end{tabular}




\begin{tabular}{|c|c|c|}
\hline Pod1 Mg (mmol/l) & 111 & $0.69(0.06)$ \\
\hline Pod1 P (mmol/l) & 111 & $1.54(1.40-1.72)$ \\
\hline \multicolumn{3}{|c|}{ Characteristics at postoperative day 3} \\
\hline Pod3 PTH (pg/mL) & 111 & $4.91(3.56-7.02)$ \\
\hline Pod3 Ca (mmol/l) & 111 & $1.89(1.83-2.00)$ \\
\hline Pod3 Mg (mmol/l) & 111 & $0.67(0.63-0.71)$ \\
\hline Pod3 P (mmol/l) & 111 & $1.67(0.34)$ \\
\hline \multicolumn{3}{|c|}{ Characteristics at postoperative day 7} \\
\hline Pod7 PTH (pg/mL) & 111 & $10.96(6.42-15.38)$ \\
\hline \multicolumn{3}{|l|}{ Pod7 Ca (mmol/l) } \\
\hline All & 111 & $2.12(0.19)$ \\
\hline Pod7 Ca $\geq 2.05(\mathrm{mmol} / \mathrm{l})$ & $75(67.57 \%)$ & $2.23(2.30-2.14)$ \\
\hline Pod7 Ca<2.05 (mmol/l) & $36(32.43 \%)$ & $1.94(1.98-1.84)$ \\
\hline \multicolumn{3}{|l|}{ Pod7 Mg (mmol/l) } \\
\hline All & 111 & $0.80(0.09)$ \\
\hline Pod7 Mg > $0.8(\mathrm{mmol} / \mathrm{l})$ & $54(48.65 \%)$ & $0.85(0.91-0.83)$ \\
\hline Pod7 Mg $\leq 0.8(\mathrm{mmol} / \mathrm{l})$ & $57(51.35 \%)$ & $0.75(0.77-0.70)$ \\
\hline \multicolumn{3}{|l|}{ Pod7 P (mmol/l) } \\
\hline All & 111 & $1.54(0.29)$ \\
\hline Pod7 P $\leq 1.51(\mathrm{mmol} / \mathrm{l})$ & $57(51.35 \%)$ & $1.36(1.45-1.20)$ \\
\hline Pod7 P>1.51 (mmol/l) & $54(48.65 \%)$ & $1.73(1.87-1.63)$ \\
\hline \multicolumn{3}{|c|}{ Characteristics at postoperative day 30} \\
\hline Pod30 PTH (pg/mL) & 111 & $30.44(20.38-42.41)$ \\
\hline Pod30 Ca (mmol/l) & 111 & $2.25(2.11-2.33)$ \\
\hline Pod30 Mg (mmol/l) & 111 & $0.86(0.80-0.89)$ \\
\hline Pod30 P (mmol/l) & 111 & $1.26(1.09-1.42)$ \\
\hline
\end{tabular}

Data are presented as $\mathrm{n} / \mathrm{N}(\%)$, mean (SD), and median (IQR). TT: total thyroidectomy; CND: central lymph node dissection; LND: lateral lymph node dissection; PGRIS: parathyroid glands remaining in situ; Pod: postoperative day 
Fig 3 ROC curves corresponding to serum ion concentrations

\begin{tabular}{|llll|}
\hline Viable & AUC & SE $^{\text {a }}$ & $95 \% \mathrm{Cl}^{\mathrm{b}}$ \\
\hline Pod7 Mg $(\mathrm{mmol} / \mathrm{l})$ & 0.788 & 0.045 & $0.700-0.860$ \\
\hline Pod7 P $(\mathrm{mmol} / \mathrm{l})$ & 0.739 & 0.049 & $0.648-0.818$ \\
\hline Pod7 $\mathrm{Ca}(\mathrm{mmol} / \mathrm{l})$ & 0.717 & 0.052 & $0.623-0.798$ \\
\hline Pod1 PTH>5.18 pg/mL & 0.720 & 0.052 & $0.627-0.801$ \\
\hline Pod3 PTH>5.6 pg/mL & 0.769 & 0.052 & $0.679-0.843$ \\
\hline Pod7 Mg and Pod7 P Combined diagnosis & 0.842 & 0.037 & $0.760-0.904$ \\
\hline
\end{tabular}

a DeLong et al., 1988

b Binomial exact

ROC: Receiver Operating Characteristic; AUC: Area under the ROC curve; SE: Standard error; Cl: Confidence interval; Pod: Postoperative day

Table 2 The diagnostic sensitivity, specificity, positive predictive value and negative predictive value of the cut-off values of serum ionized calcium, magnesium and phosphorus for normal PTH levels at Pod7

\begin{tabular}{|lllll|}
\hline & Sensitivity (\%) & Specificity (\%) & PPV (\%) & NPV (\%) \\
\hline Pod7 $\mathrm{Mg}>0.80 \mathrm{mmol} / \mathrm{I}$ & 86.21 & 64.6 & 46.3 & 93 \\
\hline Pod7 P $\leq 1.51 \mathrm{mmol} / \mathrm{I}$ & 82.76 & 59.76 & 42.1 & 90.7 \\
\hline Pod7 $\mathrm{Ca}>2.05 \mathrm{mmol} / \mathrm{I}$ & 93.10 & 46.34 & 46.2 & 84.9 \\
\hline Pod1 $\mathrm{PTH}>5.18 \mathrm{pg} / \mathrm{mL}$ & 79.31 & 62.20 & 42.6 & 89.5 \\
\hline Pod3 PTH $>5.60 \mathrm{pg} / \mathrm{mL}$ & 75.86 & 71.95 & 48.9 & 89.4 \\
\hline Pod7 $\mathrm{Mg}$ and Pod7 P Combined diagnose & 82.76 & 76.83 & 55.8 & 92.6 \\
\hline
\end{tabular}

PPV: positive predictive value; NPV: negative predictive value; Pod: postoperative day

Table 3 Univariate analysis for Pos7 PTH 


\begin{tabular}{|c|c|c|c|}
\hline Covariate & OR & $95 \% \mathrm{Cl}$ & $P$ value \\
\hline Age, years (mean $\pm S D)$ & 1.01 & $(0.98,1.05)$ & 0.531 \\
\hline Continuous sex & 1.01 & $(0.33,3.11)$ & 0.984 \\
\hline Female & \multicolumn{3}{|l|}{ Reference } \\
\hline Male & 1.01 & $(0.33,3.11)$ & 0.984 \\
\hline Vitamin D & 0.98 & $(0.93,1.04)$ & 0.541 \\
\hline Continuous scope of surgery & 0.93 & $(0.42,2.06)$ & 0.855 \\
\hline TT & \multicolumn{3}{|l|}{ Reference } \\
\hline TT+CND & 6464692.49 & $(0.00, \operatorname{lnf})$ & 0.991 \\
\hline TT+CND+LND & 4742836.60 & $(0.00, \operatorname{lnf})$ & 0.991 \\
\hline Continuous PGRIS & 0.71 & $(0.49,1.05)$ & 0.084 \\
\hline 0 & \multicolumn{3}{|l|}{ Reference } \\
\hline 1 & 6.00 & $(0.35,101.57)$ & 0.215 \\
\hline 2 & 2.33 & $(0.22,25.25)$ & 0.486 \\
\hline 3 & 1.57 & $(0.16,15.67)$ & 0.700 \\
\hline 4 & 0.78 & $(0.08,8.04)$ & 0.833 \\
\hline Pre PTH & 1.01 & $(0.99,1.03)$ & 0.369 \\
\hline Continuous Pod1 PTH & 1.49 & $(1.18,1.90)$ & 0.001 \\
\hline Pod1 PTH $>5.18$ pg/mL & 6.31 & $(2.31,17.20)$ & $<0.001$ \\
\hline Continuous Pod3 PTH & 1.39 & $(1.17,1.64)$ & $<0.001$ \\
\hline Pod3 PTH $>5.60 \mathrm{pg} / \mathrm{mL}$ & 8.06 & $(3.03,21.43)$ & $<0.001$ \\
\hline Pre Ca & 0.14 & $(0.00,14.01)$ & 0.403 \\
\hline Pod1 Ca & 3.68 & $(0.11,126.12)$ & 0.470 \\
\hline \multicolumn{4}{|l|}{ Thyroid pathology } \\
\hline Carcinoma & \multicolumn{3}{|l|}{ Reference } \\
\hline Goiter & 1.95 & $(0.31,12.30)$ & 0.477 \\
\hline Continuous Pod7 Mg & 5137891.30 & (3242.36, inf.) & $<0.001$ \\
\hline Pod7 Mg > 0.80 & 11.42 & $(3.62,36.02)$ & $<0.001$ \\
\hline Continuous Pod7 P & 0.04 & $(0.01,0.25)$ & $<0.001$ \\
\hline
\end{tabular}




\begin{tabular}{|llll|} 
Pod7 P $\leq 1.51$ & 7.13 & $(2.47,20.57)$ & $<0.001$ \\
\hline Continuous Pod7 Ca & 112.53 & $(6.38,1984.65)$ & 0.001 \\
\hline Pod7 Ca $\geq 2.05$ & 9.77 & $(2.17,43.88)$ & 0.003 \\
\hline
\end{tabular}

TT: total thyroidectomy; CND: central lymph node dissection; LND: lateral lymph node dissection; PGRIS: parathyroid glands remaining in situ; Pre: preoperative; Pod: postoperative day

Table 4 Multivariate analysis of factors affecting the Pod7 PTH return to normal

\begin{tabular}{|llll|}
\hline Variables & OR & $(95 \% \mathrm{Cl})$ & $P$ value \\
\hline PGRIS & 0.517 & $(0.290,0.921)$ & 0.021 \\
\hline Pod1 $\mathrm{PTH}>5.18 \mathrm{pg} / \mathrm{mL}$ & 3.439 & $(0.968,12.222)$ & 0.056 \\
\hline Pod3 $\mathrm{PTH}>5.60 \mathrm{pg} / \mathrm{mL}$ & 3.745 & $(1.078,13.008)$ & 0.038 \\
\hline Pod7 $\mathrm{Mg}>0.80$ & 9.221 & $(2.374,35.823)$ & 0.001 \\
\hline Pod7 P $\leq 1.51$ & 4.475 & $(1.262,15.864)$ & 0.020 \\
\hline
\end{tabular}

Pre: preoperative; Pod: postoperative day

\section{Figures}




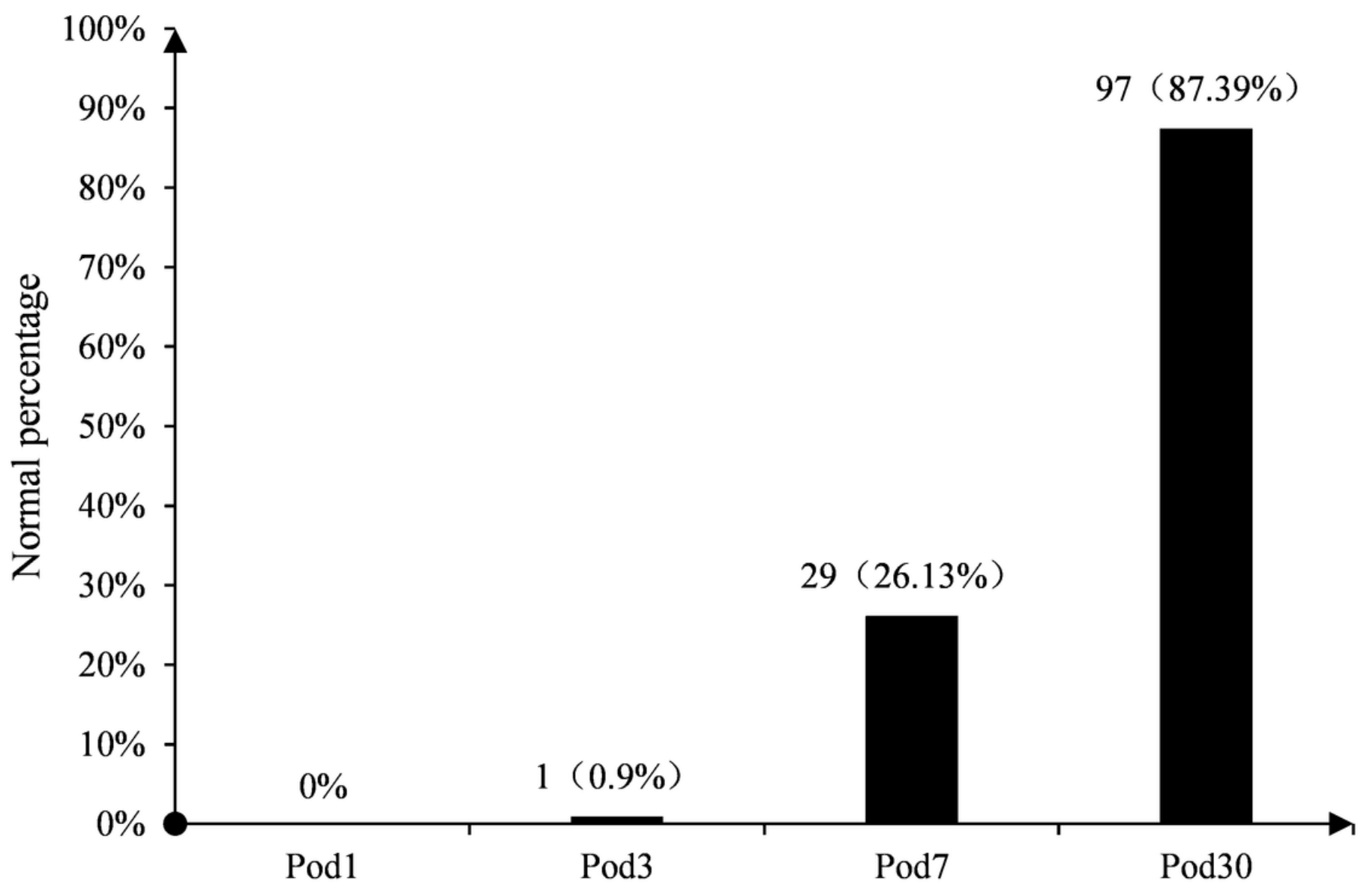

Figure 1

PTH returned to normal on days $1,3,7$, and 30 after surgery. Pod: postoperative day 


$$
\underset{\mathrm{Ca}}{\sim}-\mathrm{Mg} \longrightarrow \mathrm{P}
$$

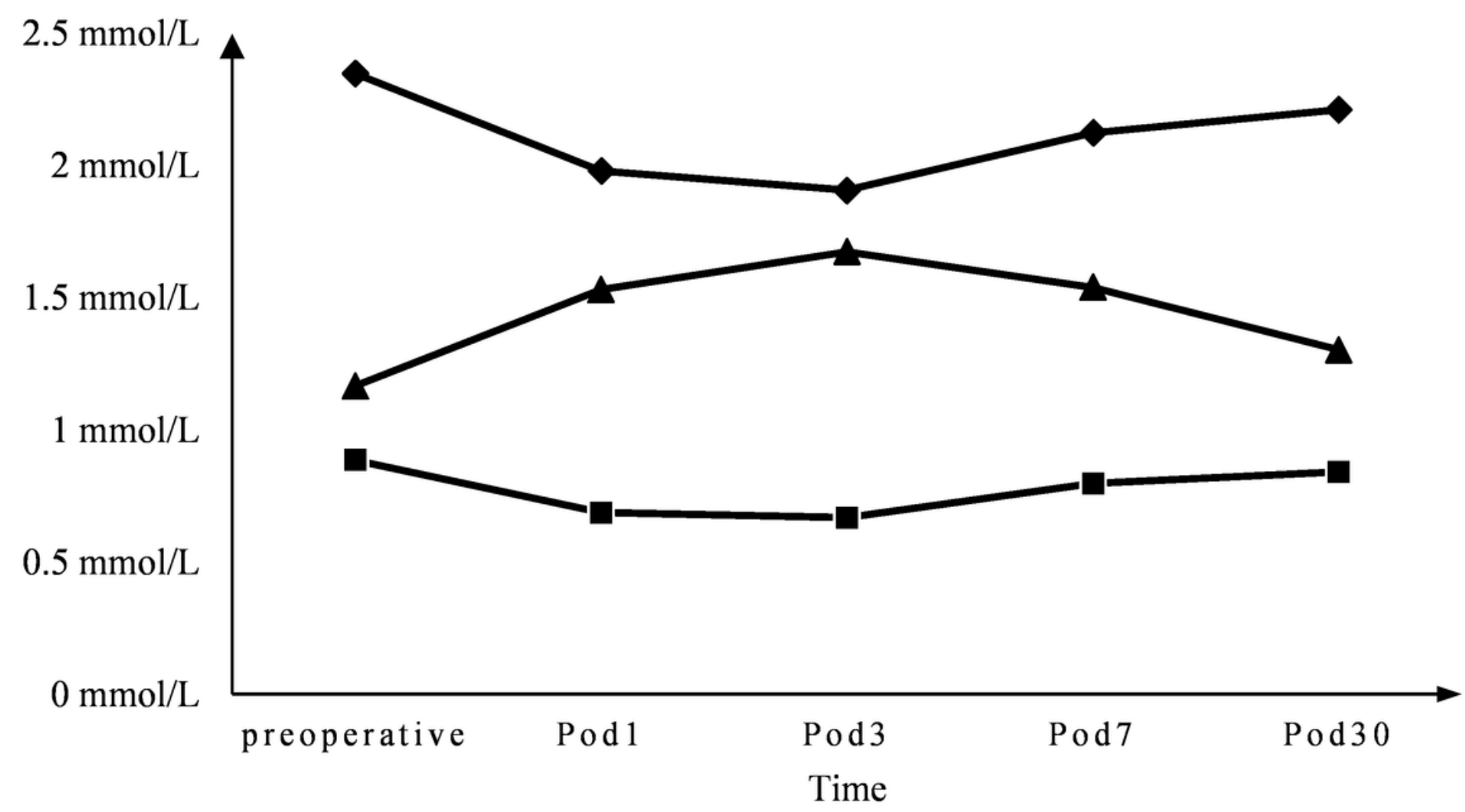

\section{Figure 2}

Change trend in serum ionized $\mathrm{Ca}, \mathrm{Mg}$ and $\mathrm{P}$ before and after thyroidectomy . Pod: postoperative day 


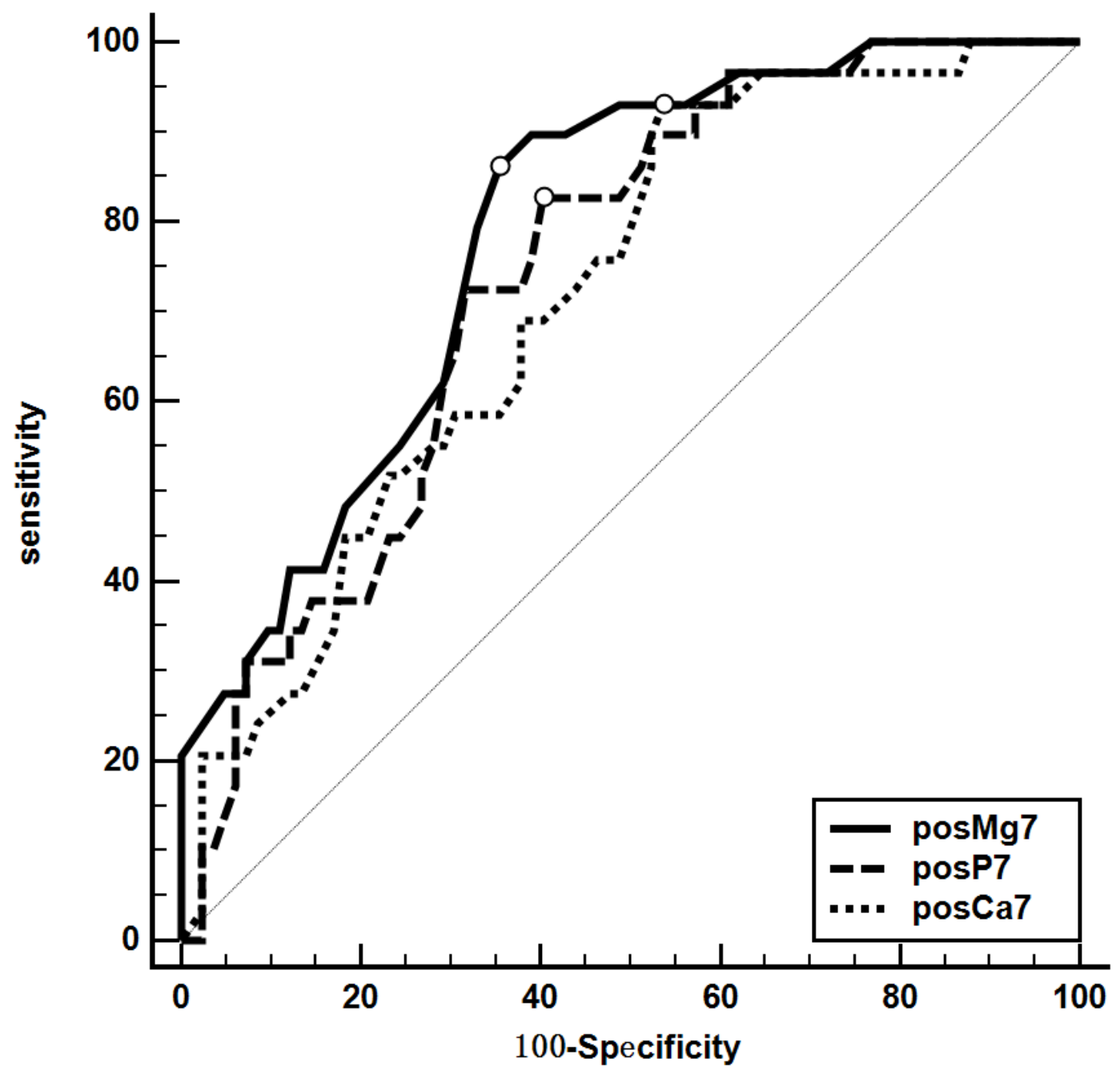

Figure 3

ROC curves corresponding to serum ion concentrations 